\title{
Maize 9-Lipoxygenase ZmLOX3 Controls Development, Root-Specific Expression of Defense Genes, and Resistance to Root-Knot Nematodes
}

\author{
Xiquan Gao, ${ }^{1}$ James Starr, ${ }^{1}$ Cornelia Göbel, ${ }^{2}$ Jürgen Engelberth, ${ }^{3,4}$ Ivo Feussner, ${ }^{2}$ James Tumlinson, ${ }^{3}$ \\ and Michael Kolomiets ${ }^{1}$ \\ ${ }^{1}$ Department of Plant Pathology and Microbiology, Texas A\&M University, TAMU 2132, College Station, 77843-2132, U.S.A.; \\ ${ }^{2}$ Department of Plant Biochemistry, Albrecht-von-Haller-Institute for Plant Sciences, Georg-August University Göttingen, \\ Justus-von-Liebig-Weg 11, D37077 Göttingen, Germany; ${ }^{3}$ Department of Entomology, Pennsylvania State University, \\ University Park 16802, U.S.A.; ${ }^{4}$ Department of Biology, The University of Texas at San Antonio, One UTSA Circle, San \\ Antonio 78249, U.S.A.
}

Submitted 13 May 2007. Accepted 31 August 2007.

Root-knot nematodes (RKN) are severe pests of maize. Although lipoxygenase (LOX) pathways and their oxylipin products have been implicated in plant-nematode interactions, prior to this report there was no conclusive genetic evidence for the function of any plant LOX gene in such interactions. We showed that expression of a maize 9-LOX

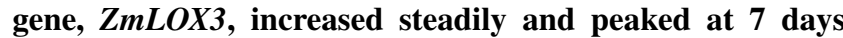
after inoculation with Meloidogyne incognita RKN. Mu-insertional lox3-4 mutants displayed increased attractiveness to RKN and an increased number of juveniles and eggs. A set of jasmonic acid (JA)- and ethylene (ET)-responsive and biosynthetic genes as well as salicylic acid (SA)-dependent genes were overexpressed specifically in the roots of lox3-4 mutants. Consistent with this, levels of JA, SA, and ET were elevated in lox3-4 mutant roots, but not in leaves. Unlike wild types, in lox3-4 mutant roots, a phenylalanine ammonia lyase $(P A L)$ gene was not $\mathrm{RKN}$-inducible, suggesting a role for PAL-mediated metabolism in nematode resistance. In addition to these alterations in the defense status of roots, lox 3-4 knockout mutants displayed precocious senescence and reduced root length and plant height compared with the wild type, suggesting that $\mathrm{ZmLOX3}$ is required for normal plant development. Taken together, our data indicate that the ZmLOX3-mediated pathway may act as a root-specific suppressor of all three major defense signaling pathways to channel plant energy into growth processes, but is required for normal levels of resistance against nematodes.

Additional keywords: 12-oxo-phytodienoic acid, fatty acid metabolism, root growth.

The root-knot nematodes ( $\mathrm{RKN})$, Meloidogyne spp., are unique pathogens in that they are strict obligate biotrophs but have a host range of hundreds, if not thousands, of plant species from a wide range of families. Meloidogyne incognita is an aggressive parasite of maize, especially in the sandy soils of the

Corresponding author: Michael Kolomiets; Telephone: +1.979 .458 .4624 ; Fax: +1.979.845.6483; E-mail: kolomiets@tamu.edu

* The $\boldsymbol{e}$-Xtra logo stands for "electronic extra" and indicates that Figure 3 appears in color online. southern coastal plains region of the United States (Windham 1998). In contrast to our understanding of plant host defense responses to fungal, bacterial, and viral infections, the signal transduction pathways and the defense genes involved in the resistance or susceptibility mechanisms to nematodes are poorly understood. Recent reports showed that genes of secondary metabolism, especially those involved in lipid metabolism, may play a key role in plant interactions with nematodes (Abad et al. 2003; Gheysen and Fenoll 2002; Veronica et al. 2006; Williamson 1999). Microarray-based expression profiling indicated that several fatty acid metabolism genes, including lipoxygenases (LOX), patatin-like protein 1 (PLP1), and 12oxo-phytodienoate reductase (OPR), are induced in susceptible soybean roots in response to soybean cyst nematode infection (Alkharouf et al. 2006). In addition to the transcriptional activation, LOX activity also was increased in pea roots (Leone et al. 2001) and soybean roots (Alkharouf et al. 2006) upon infection with cyst nematodes. These data implicated lipid metabolic pathways in the defense responses of plants to RKN. However, to date, no conclusive genetic evidence of biological significance of this induction of lipid metabolism genes for plant resistance mechanisms has been provided.

Plant LOXs catalyze the incorporation of molecular oxygen into free polyunsaturated fatty acids, primarily linoleic (C18:2) and linolenic $(\mathrm{C} 18: 3)$ acids, at either position 9 or 13 , in a stereospecific manner and, therefore, are referred to as linoleate 9-LOXs or 13-LOXs (Howe and Schilmiller 2002). The LOX immediate products, fatty acid hydroperoxides, then are used by at least six different multienzyme branches to form a large number of oxygenated fatty acids or so-called oxylipins (Blee 2002). Due to the generation of functionally diverse oxylipins, LOX pathways have been implicated in several physiological processes, including plant growth and development, senescence, resistance to insects and pathogens, and environmental stress (Howe and Schilmiller 2002; Porta and Rocha-Sosa 2002). To date, the best elucidated branches of the LOX pathway are those initiated by the 13-LOX-catalyzed oxygenation of C18:3: the allene oxide synthase (AOS) branch and the hydroperoxide lyase (HPL) branch (Feussner and Wasternack 2002). The AOS branch, also known as the octadecanoid pathway, converts (13S)-hydroperoxy linolenic acid (13-HPOTE) into a diverse group of jasmonates, including the octadecanoate 12oxo-phytodienoic acid (12-OPDA) and jasmonic acid (JA) (Feussner and Wasternack 2002). The HPL branch competes 
for $13 S$-HPOTE with the AOS pathway to produce a number of volatile C-6 aldehydes and alcohols, also referred to as green leaf volatiles (GLV). Both jasmonates and GLV are potent signals that regulate expression of numerous defense-related and developmental genes (Bate and Rothstein 1998; Birkett et al. 2000; Engelberth et al. 2007; Kishimoto et al. 2006). Despite considerable progress in our understanding of the defenserelated significance of the 13-LOX-derived oxylipins, the function of 9-LOXs and their metabolites is currently unclear. Accumulating evidence indicates that the 9-LOX pathways might play important roles in defense against diverse pathogens (Fammartino et al. 2007; Göbel et al. 2001, 2002, 2003; Hamberg et al. 2003; Kolomiets et al. 2000). This is commonly explained by the fact that 9-LOX-derived oxylipins act as signals to regulate programmed cell death (Cacas et al. 2005; Rusterucci et al. 1999) or by their potent antimicrobial activity (Göbel et al. 2001; Prost et al. 2005). In addition to having a role in defense responses to pathogens, 9-LOXs also are implicated in plant developmental processes. A specific 9LOX gene is transiently induced during potato tuber growth, and its antisense suppression resulted in reduced tuber size (Kolomiets et al. 2001). In addition to multiple reports of increased LOX activity during germination and active vegetative growth of plants (Feussner and Wasternack 2002), expression of 9-LOXs is induced to high levels during seed development in almond (Santino et al. 2005) and maize (Jensen et al. 1997). A function for the 9-LOX-derived metabolites in the regulation of root growth and development has been demonstrated convincingly in a recent study of the Arabidopsis 9LOX mutants that displayed an increased number of lateral roots (Vellosillo et al. 2007).

This study provides compelling evidence for the functional relevance of a 9-LOX biosynthetic pathway in maize for growth and development and resistance to RKN by showing that disruption of the root-specific 9-LOX gene $Z m L O X 3$ results in suppressed plant growth and increased attraction to and reproduction of RKN. In an attempt to elucidate the molecular basis of increased susceptibility of lox3 mutants to $\mathrm{RKN}$, we found that, except for phenylalanine ammonia lyase $(P A L)$, multiple JA-, salicylic acid (SA)-, and ethylene (ET)responsive defense genes were overexpressed in lox3-4 mutant roots but not in leaves. Corroborating this finding, lox3-4 mutant roots but not leaves displayed elevated levels of JA, SA, and overproduction of ET. Taken together, these data suggest that ZmLOX3-mediated metabolism has a strong root-specific suppressor activity of major defense signaling pathways. Despite this heightened state of defense, lox3-4 mutants are more susceptible to RKN. We hypothesize that this increased susceptibility is due to inability of the mutants to induce PAL-mediated metabolism as well as their increased levels of nematodeattracting ET.

\section{RESULTS}

\section{lox3-4 Mutants exhibit developmental defects.}

In our recent report, we showed that, among the four mutant alleles of ZmLOX3 generated by an insertion of Mutator transposable elements in its coding sequence, exonic insertion of a $M u$ element in the lox3-4 allele resulted in complete suppression of gene expression and reduction of several 9LOX-derived oxylipins in germinating embryos (Gao et al. 2007). These data suggested that lox3-4 is a true null allele of the $Z m L O X 3$ gene. Because B73 is a model maize line, the genome of which is being sequenced, we generated nearisogenic lines (NILs) that are either null mutants (lox3-4) or wild types for the $Z m L O X 3$ locus in $\mathrm{B} 73$ genetic background. To compensate for the lack of independent null alleles, all experiments presented in this study were carried out using several independently bred mutant and wild-type NILs at the $\mathrm{BC}_{4} \mathrm{~F}_{5}$ genetic stage. Because $Z m L O X 3$ was induced to high levels during early stages of seed germination (formerly called cssap92 by Wilson and associates [2001]), we carefully examined whether disruption of this gene results in any morphological changes during seedling and mature plant growth. The lox3-4 seedlings displayed reduced root and shoot length compared with the wild types at 5 days after imbibition (Fig. 1). Heterozygous seedlings had intermediate root and shoot length (Fig. 1A and B), indicating that this trait is inherited in a semidominant fashion and providing additional support that developmental alterations observed are indeed due to $\mathrm{ZmLOX3}$ mutation. This retardation in growth can be explained partially by slightly slower germination of the mutant seed (Fig. 1C); however, this seems unlikely because reduced growth was evident throughout all stages of plant development; mature lox3-4 mutant plants were approximately 25 to $30 \%$ shorter than wild types (Fig. 1D and F). Moreover, lox3-4 mutants senesced approximately 10 days earlier compared with the wild type (Fig. 1D and E), suggesting a shorter life cycle. No difference was observed in any kernel morphological characteristics, including weight (data not shown).

\section{lox3-4 Mutants are more susceptible to RKN compared with near-isogenic wild types.}

Because $Z m L O X 3$ is expressed primarily in the underground organs (Gao et al. 2007), we investigated whether this gene may have a role in defense responses to RKN by studying expression of $Z m L O X 3$ in response to RKN infection and testing the effect of disruption of this gene on maize resistance or susceptibility to RKN. Northern blot analysis showed that RKN infection induced steady-state transcript accumulation of ZmLOX3 in wild-type roots peaking at 7 days postinfection (dpi) and then declined to a lower level. As expected, no transcripts were detected in lox3-4 mutant roots upon RKN infection (Fig. 2). As a measure of susceptibility to RKN, nematode eggs were counted from both lox3-4 mutant and wild-type roots 8 weeks after infection. Significantly more nematode eggs (analysis of variance [ANOVA], $P<0.05$ ) were extracted from the mutant roots (approximately 21,000 eggs per gram of roots) than from wild-type roots (approximately 10,000 eggs per gram of roots) (Fig. 3A). Furthermore, the number of galls per plant in wild types and mutants were, on average, 61.4 and 85.4, respectively, at $7 \mathrm{dpi}$. At $16 \mathrm{dpi}$, the majority of nematodes inside the roots were females, all of which just started laying eggs. At $28 \mathrm{dpi}$, the number of eggs per female in wild types and mutants were, on average, 86.7 and 160.3, respectively. However, we did not observe any dramatic effect of increased susceptibility on the overall performance of lox3-4 mutant plants infected with RKN compared with infected wild types in terms of reduction of height or fresh or dry weight. By using the six-arm olfactometer system (Fig. 3B), we found that mutant roots attracted almost twice as many second-stage juveniles (J2) as did wild-type roots (ANOVA, $P<0.05$ ) (Fig. 3C). This experiment was repeated three times and consistent results were obtained. Collectively, these data suggest that the lox3-4 mutant was more susceptible to RKN than the nearisogenic wild type, indicating that functional $\mathrm{ZmLOX} 3$ is an important component of the defense mechanism of maize against RKN.

\section{Genes of the AOS- and the HPL-pathway branches are overexpressed in lox $3-4$ mutant roots.}

To shed light on the molecular mechanisms underpinning the increased susceptibility of the lox3-4 mutants to RKN, we 
elucidated expression of the genes implicated in the biosynthesis of JA (the AOS branch) and GLV (the HPL branch) in lox34 mutants and wild-type NILs. Previously, we cloned and sequenced the entire maize LOX and OPR gene families containing 12 and 8 genes, respectively (Kolomiets et al. 2004; Zhang et al. 2005). Among maize LOXs, ZmLOX5 is predominantly 9-LOX whereas ZmLOX8 and ZmLOX10 are 13-LOXs (Nemchenko et al. 2006; M. Kolomiets and I. Feussner, unpublished data). ZmLOX8, ZmAOS, ZmAOC, and ZmOPR7 or ZmOPR8 are implicated in JA biosynthesis (Zhang et al. 2005), whereas ZmLOX10 and HPL are most likely GLV-producing enzymes (Nemchenko et al. 2006). All LOX genes tested in this study were upregulated in wild-type roots in response to RKN infection (Fig. 4), peaking between 7 and $13 \mathrm{dpi}$, followed by a subsequent reduction at $16 \mathrm{dpi}$. Similarly, both $Z m A O S$ and $Z m A O C$ showed maximum transcript levels at 13 dpi. $Z m L O X 8$ was expressed at relatively higher levels in noninfected lox3-4 mutant roots but was induced to even higher levels at 10 dpi in wild-type roots, followed by a marked decrease thereafter. Although transcript levels of $Z m L O X 5, Z m A O C$, and $Z m A O S$ were detectable at low levels in the noninfected ( 0 time point) wild-type roots and were increased upon infection, their steady-state mRNAs accumulated to high levels in unchallenged as well as challenged mutant roots at all time points tested. Despite extremely high sequence identity between putative JA-producing ZmOPR7 and ZmOPR8 genes (Zhang et al. 2005), they displayed dissimilar expression patterns in response to RKN infection. Whereas ZmOPR8 transcripts were not detected in uninfected wild-type roots but were induced at 13 dpi (Fig. 4), ZmOPR7 was highly expressed in wild-type and mutant roots throughout the experiment (data not shown). In contrast to the wild type, in the lox3-4 mutant root $\mathrm{ZmOPR} 8$ transcripts accumulated abundantly in uninfected roots and were upregulated to even higher levels upon infection reaching maximum at $10 \mathrm{dpi}$ (Fig. 4). Similar to the AOS-pathway
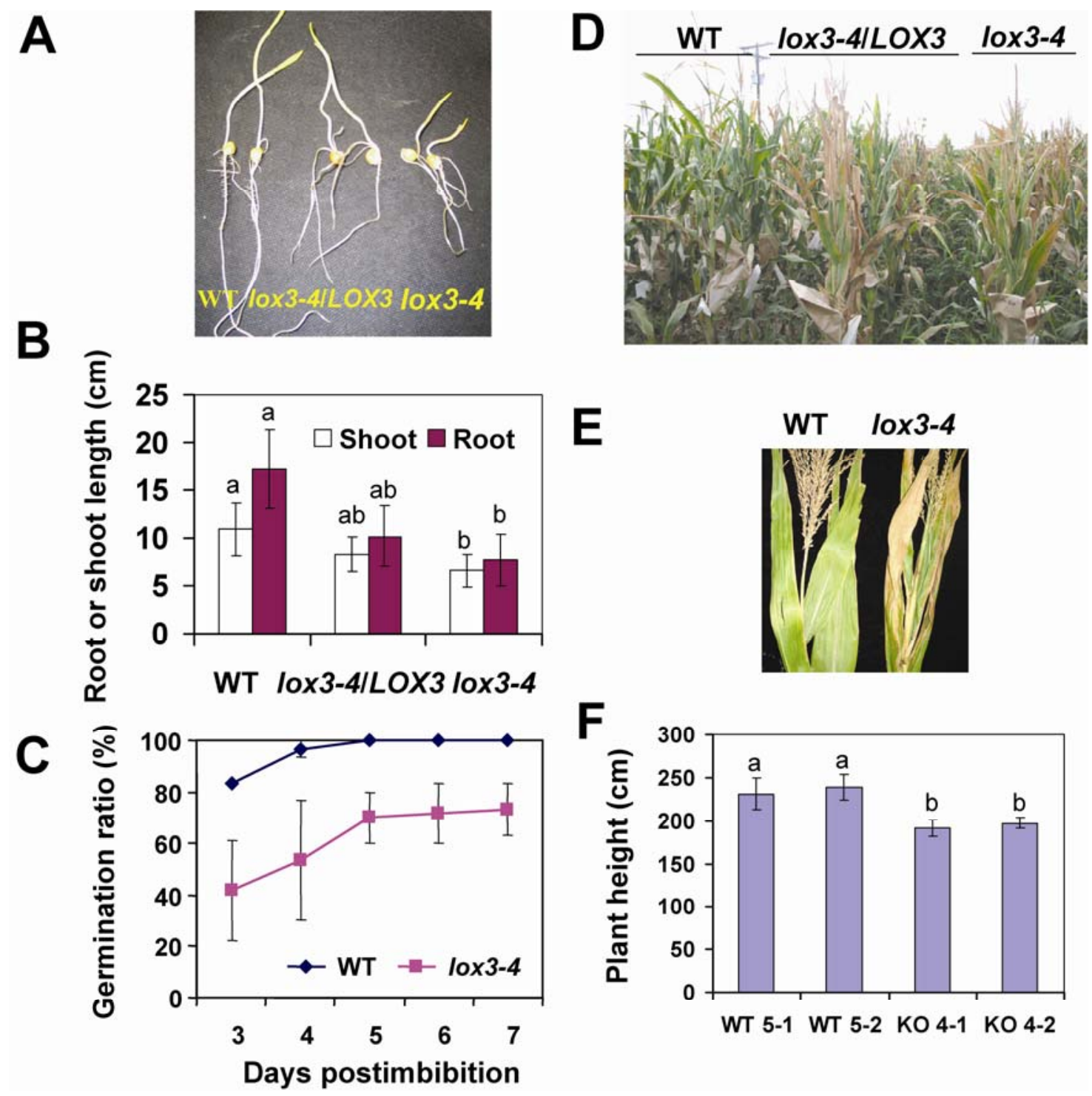

F

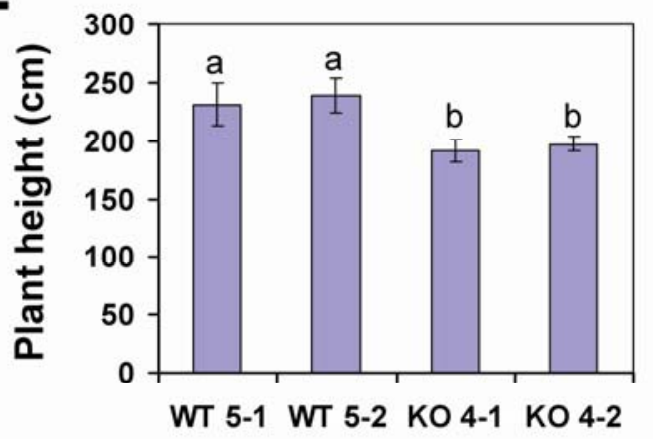

Fig. 1. lox3-4 Mutants displayed precocious senescence and reduced root length and plant height compared with the wild type (WT). A, lox3-4 Mutant and WT seed were germinated in plastic jars at 25 to $28^{\circ} \mathrm{C}$ in the dark, and the seedlings were photographed 5 days after imbibition. B, Shoot and root lengths were measured 5 days after imbibition. WT, wild type; lox3-4/LOX3, heterozygote; lox3-4, homozygous mutant. The data were expressed as mean \pm standard deviation (SD) from 20 seedlings. C, Germination of lox3-4 mutant seed was delayed compared with near-isogenic line WT. The data are shown as average from two independent experiments. D and E, lox3-4 Homozygous and heterozygous mutants are retarded in their growth and senesce about 10 days earlier compared with near-isogenic WTs grown in a field. The pictures were taken approximately 4 weeks after midsilking. F, Plant height was measured 2 weeks after midsilking. The data were expressed as mean $\pm \mathrm{SD}(n=$ approximately 20 to 25$)$. Different letters on the top of bars denote a significant difference $(P<$ 0.05 , analysis of variance) $\mathbf{B}$, within the same tissue or $\mathbf{F}$, between genotypes analyzed by the SPSS program. 
branch genes, the transcripts of putative HPL-pathway genes ZmLOX10 (Nemchenko et al. 2006) and ZmHPL were not detected in unchallenged wild-type roots but were transiently induced upon RKN infection, reaching their highest level at 7 dpi. In contrast to the wild type, their mRNA levels were the highest in uninfected lox3-4 mutant roots but slightly decreased in response to $\mathrm{RKN}$ infection.

\section{Days postinfection}

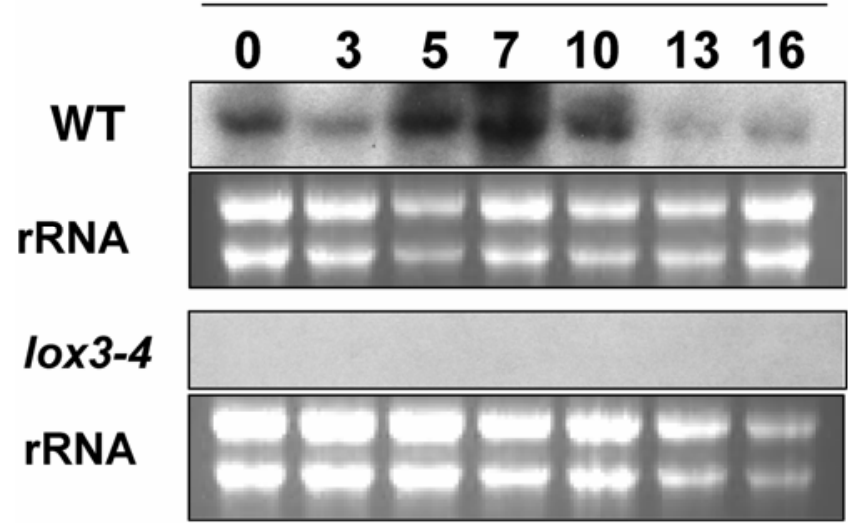

Fig. 2. Northern blot analysis of $Z m L O X 3$ expression in response to rootknot nematode (Meloidogyne incognita) infection in roots of lox3-4 mutant and near-isogenic wild-type (WT) plants at indicated times. Equal loading of RNA was tested by visualizing ethidium bromide staining of rRNA. Experiments were repeated at least three times and representative blots are shown.
SA-, JA-, and ET-responsive genes are overexpressed in lox 3-4 mutant roots.

Similar to the putative JA-producing genes, transcripts of the JA-responsive maize proteinase inhibitor $(M P I)$ gene (Cordero et al. 1994) were not detectable in unchallenged wild-type roots but were induced transiently in response to RKN infection, peaking at 13 dpi (Fig. 5). In lox3-4 mutants, however, MPI was expressed constitutively reaching levels comparable only with those found in the wild types at $13 \mathrm{dpi}$, its maximal levels. SA-responsive genes, such as those encoding pathogenesisrelated (PR) proteins, have been well documented to be associated with defense responses against diverse pathogens. However, the function of SA-responsive genes in plant-RKN interaction processes is currently obscure. Semiquantitative reversetranscription polymerase chain reaction (sqRT-PCR) analysis showed that $P R 1$ (Fig. 5) was expressed at relatively low levels in uninfected wild-type roots but was induced at $16 \mathrm{dpi}$, the slowest responding of all the defense genes tested. In the mutant roots, PRI was constitutively expressed (Fig. 5). Perhaps the most surprising finding of this study was the expression pattern of the PAL gene. PAL catalyzes the first step of biosynthesis of phenylpropanoid compounds, such as cinnamic and benzoic acids, leading to the production of SA. Despite the fact that PAL genes were not well studied in maize, it has been shown that PAL is involved in defense-related processes (Hammerschmidt 1999). Transcript levels of this gene were strongly induced in response to $\mathrm{RKN}$ infection in wild-type roots, peaking at $10 \mathrm{dpi}$. However, $P A L$ transcripts were barely detectable in mutant roots infected with RKN throughout the time course of the experiment (Fig. 5). Sequencing of the $P A L$ PCR products at different timepoints after infection revealed
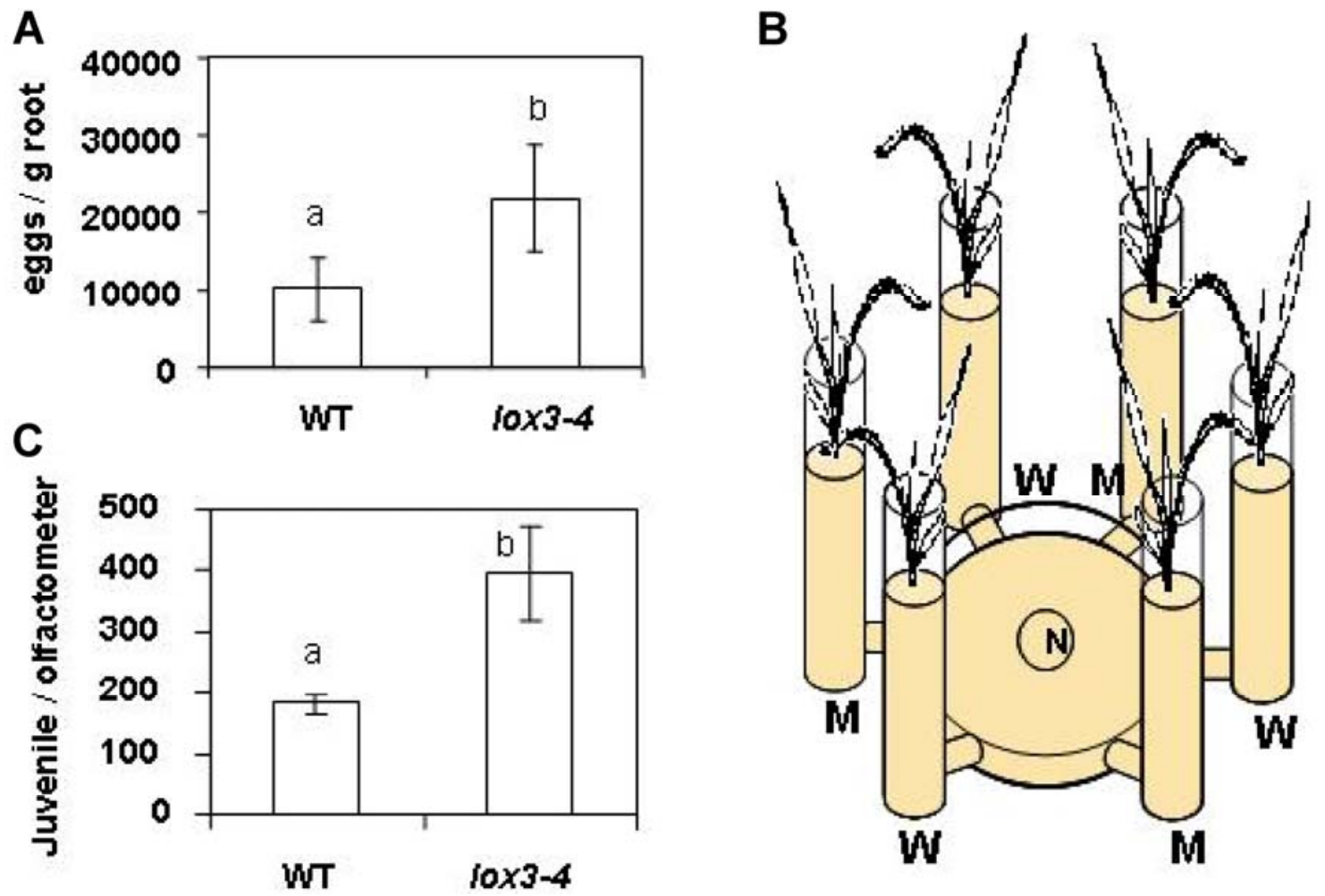

Fig. 3. lox3-4 Mutants exhibit increased susceptibility to root-knot nematode (RKN) Meloidogyne incognita. A, Number of RKN eggs produced on ZmLOX3 wild-type (WT) and mutant plants. The data were expressed as means and analyzed using the general linear model of SAS (SAS Institute, Inc., Cary, NC, U.S.A.). Different letters indicate significance at $5 \%$ level. The experiment was repeated three times and consistent results were obtained. B, Schematic presentation of the six-arm olfactometer system used in nematode attraction assays. W, wild type; M, lox3-4 mutant; N, the point of inoculation with nematode juveniles. C, RKN juveniles are significantly more attracted to lox3-4 mutant roots compared with WTs. The number of juveniles that migrated to either WT or mutant roots was counted 4 days after inoculation and was expressed as the average from three olfactometers. The assay was replicated three times with consistent results. Different letters on the top of bars denote a significant difference $(P<0.05$, analysis of variance) between genotypes analyzed by the SPSS program. 
that a single gene product (GenBank accession number L77912) was amplified.

Levels of 9-oxylipins are reduced but endogenous JA, SA, OPDA, and ET levels are increased in lox3-4 mutant roots.

Because ZmLOX3 is predominantly a 9-LOX (Wilson et al. 2001), we quantified major plant 9-oxylipins that may be specifically produced by the ZmLOX3-mediated pathway. Oxylipin profiling was conducted by using gas chromatography/ electron impact mass spectrometry (GC/EI-MS) in combination with reversed phase high-performance liquid chromatography (RP-HPLC) in lox3-4 mutant versus wild-type roots and leaves. The levels of several 9-oxylipins, including 9-hydroxyoctadecadienoic acid (9-HODE), 9-keto-octadecadienoic acid (9-KODE), and 9-keto-octadecatrienoic acid (9-KOTE), were reduced significantly in mutant roots compared with the wild type (ANOVA, $P<0.05$ ) (Fig. 6A and B). Similar reduction of 9-LOX derivatives also has been observed in the embryos of the lox3-4 kernels (Gao et al. 2007). Corroborating our previous finding that $\mathrm{ZmLOX3}$ is expressed in an underground organspecific manner (Gao et al. 2007), no reduction of 9-oxylipins was detected in the lox3-4 mutant leaves. Notably, C18:2-derived oxylipins (9-HODE and 9-KODE) were dominant over C18:3-derived oxylipins (9-HOTE and 9-KOTE) in both wildtype and mutant roots. This can be explained by the well-documented higher content of C18:2 compared with C18:3 in plant roots (Stumpe et al. 2006).

Because JA-biosynthetic genes and JA- as well as SA-responsive genes were expressed constitutively in the uninfected lox3-4 mutant roots, we investigated whether mutant roots displayed increased endogenous levels of JA and SA. JA and SA levels were measured simultaneously in roots and leaves of nontreated 2-week-old seedlings at the V3 developmental stage, the same stage at which RKN infection experiments were carried out. The JA and SA contents in the leaves were not significantly different between wild-type and mutant seedlings (Fig. 6C and D). However, in mutant roots, levels of both JA and SA were approximately twofold greater than those in wild-type roots (ANOVA, $P<0.05$ ). Taken together, these data suggest that one function of the $Z m L O X 3$-mediated pathway is root-specific suppression of biosynthesis of JA and SA. This was corroborated by our observation that JA-responsive genes such as MPI, ZmOPR8 (Zhang et al. 2005), and ZmLOX10 (Nemchenko et al. 2006) and putative JA biosynthetic genes ZmLOX8, ZmAOS, ZmAOC, and ZmOPR8 (Zhang et al. 2005), as well as SA-responsive $P R 1$, were overexpressed in the mutant roots only (Figs. 4 and 5), not in leaves (data not shown). In addition to the elevated levels of JA, the levels of 12-oxophytodienoic acid (12-OPDA), a jasmonate precursor, were relatively higher in the mutant roots compared with the wild type at 0 time point (noninfected roots) but were decreased, albeit not significantly, after RKN infection (Fig. 7A). However, no significant alteration of the levels of JA and SA was observed in either the wild type or lox3-4 mutant at 3,10 , or 16 dpi in three independent experiments (data not shown).

Accumulating evidence suggests that ET-mediated signaling acts synergistically with JA-signaling pathways in diverse defense response events (Schmelz et al. 2003; van Loon et al. 2006). Because lox3-4 mutant roots displayed elevated JA levels, we hypothesized that this may lead to increased ET production. To test this hypothesis, we measured the amount of ET in the head space of excised maize leaves and roots of the V3 stage seedlings. The lox3-4 mutants released more ET from both leaves and roots compared with the wild types (Fig. 6E). Whereas ET content was only slightly greater but not statistically significant in mutant leaves, mutant roots produced nearly 2.5-fold higher ET levels compared with wild types, and this difference was statistically significant $(P<0.05)$ (Fig. 6E). In agreement with this result, 1-aminocyclopropane-1-carboxylic acid (ACC) oxidase (ACO31, AY359573), an ET biosynthetic gene, was expressed at a very high level in lox3-4 mutant roots, whereas transcripts of this gene were below detection level in

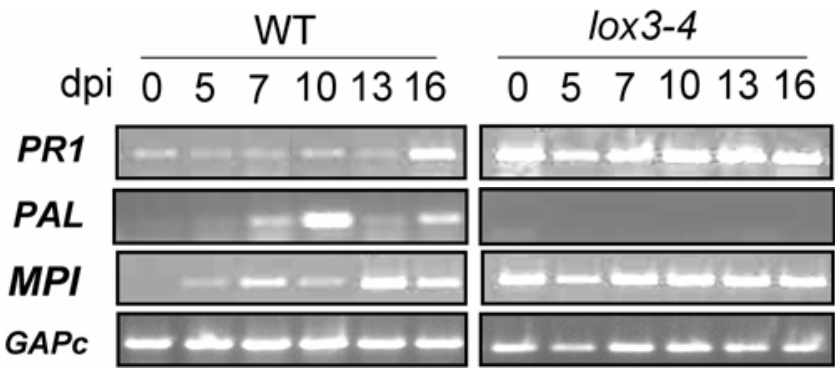

Fig. 5. Expression of the pathogenesis-related protein $1(P R 1)$, phenylalanine ammonia lyase $(P A L)$, and maize proteinase inhibitor $(M P I)$ genes in response to infection with root-knot nematode Meloidogyne incognita in maize lox3-4 mutant and near-isogenic wild-type (WT) plants as measured by semiquantitative reverse-transcription polymerase chain reaction; dpi, days postinfection. Expression of glyceraldehyde-3-phosphate-dehydrogenase $(G A P C)$ was used as a quantitative standard. Two independent experiments were conducted and similar results were obtained.

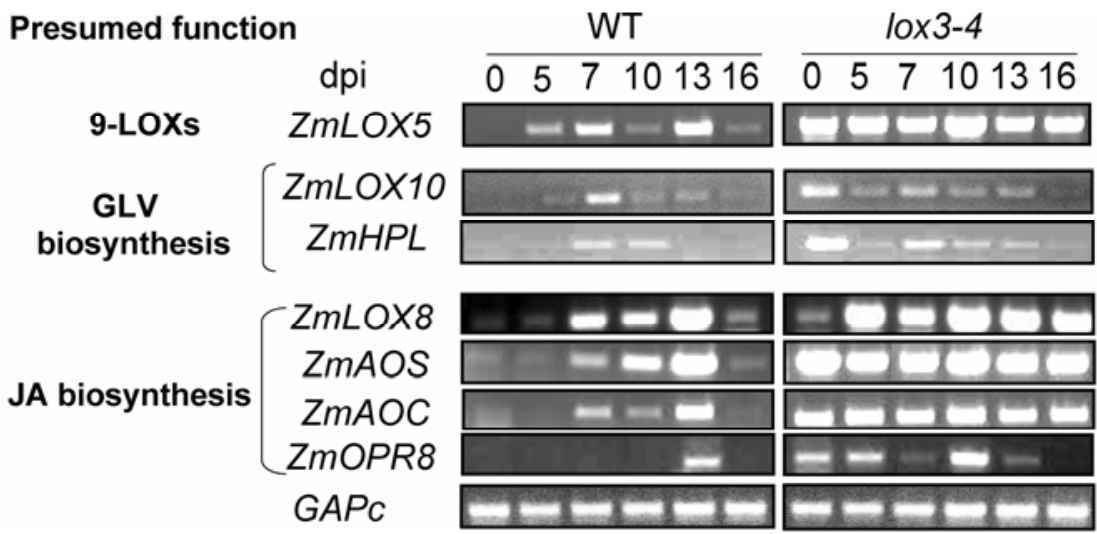

Fig. 4. Expression of 9-lipoxygenase (9-LOX), green leaf volatile (GLV)- and jasmonic acid (JA)-biosynthetic and JA-responsive genes in lox3-4 mutant and near-isogenic wild-type (WT) roots upon infection with root-knot nematode Meloidogyne incognita as measured by semiquantitative reverse-transcription polymerase chain reaction. $H P L$, hydroperoxide lyase; ZmAOS, allene oxide synthase; ZmAOC, allene oxide cyclase; ZmOPR8, 12-oxo-phytodienoic acid reductase 8; dpi, days postinfection. Expression of glyceraldehyde-3-phosphate-dehydrogenase (GAPc) was used as a quantitative standard. Two independent experiments were conducted and similar results were obtained. 
the wild type. In contrast to roots, no difference in the ZmACO31 mRNA levels was found between wild-type and mutant leaves (Fig. 6F), suggesting that disruption of $Z m L O X 3$ resulted in root-specific overexpression of this gene. Surprisingly, RKN infection did not enhance ET production; rather, there was a moderate decrease in both wild-type and mutant roots (Fig. 7B). Nevertheless, at all time points tested, ET was produced at significantly higher levels in the mutant roots relative to the wild type (Fig. 7B), supporting our hypothesis that increased attractiveness and susceptibility of the lox3-4 mutant to RKN might be due to elevated biosynthesis of ET in the mutant roots.
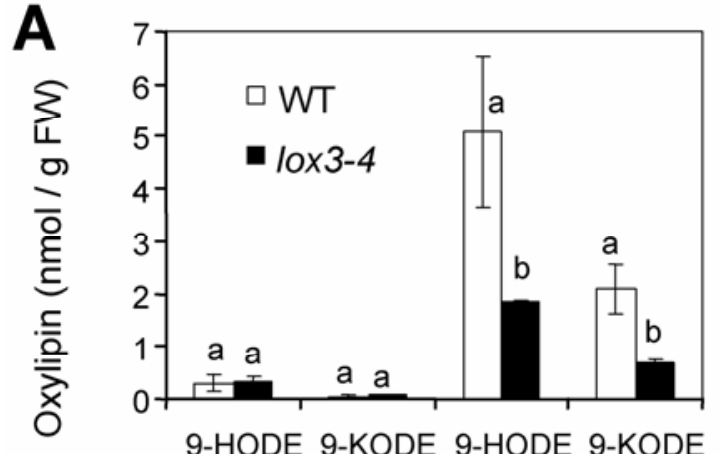

C
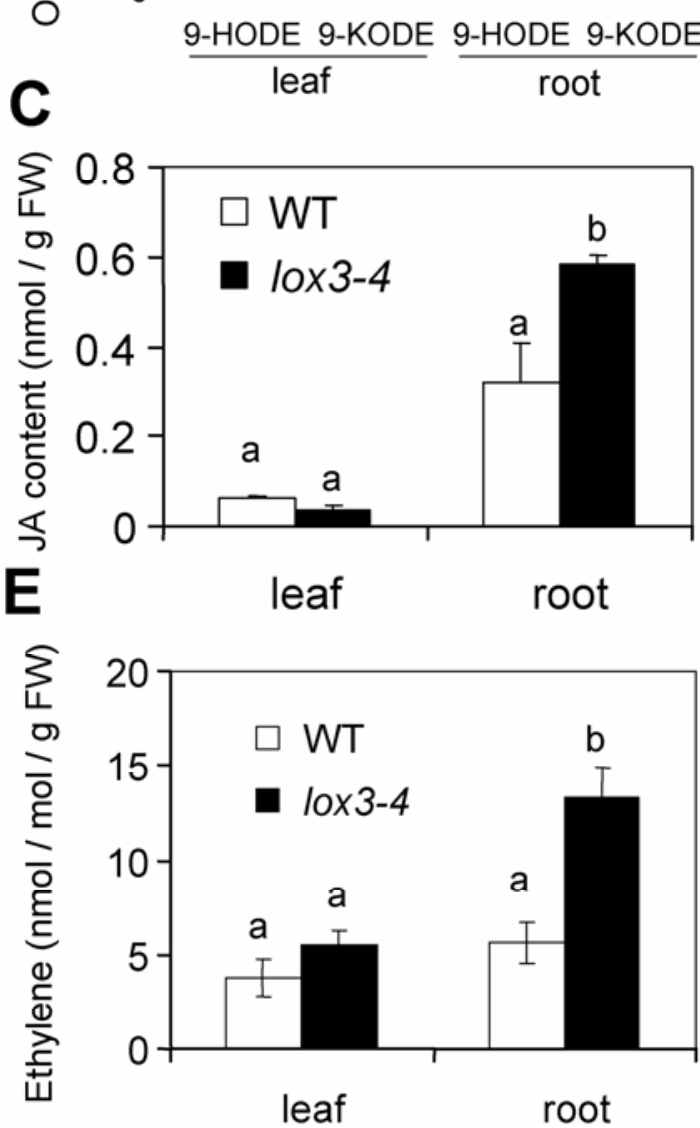

\section{DISCUSSION}

ZmLOX3 affects parasitism of maize by RKN.

Numerous studies provide abundant evidence of key roles that 13-LOX-derived oxylipins such as jasmonates and GLV play in plant resistance mechanisms against diverse pathogens and pests. However, little is known about the physiological functions of 9-LOXs and their metabolites in plant developmental or defense-related processes, let alone their involvement in the interactions of plants with nematodes. Except for a few previous reports suggesting that LOX activity and transcript accumulation were stimulated in response to nematode infection (Leone et al.
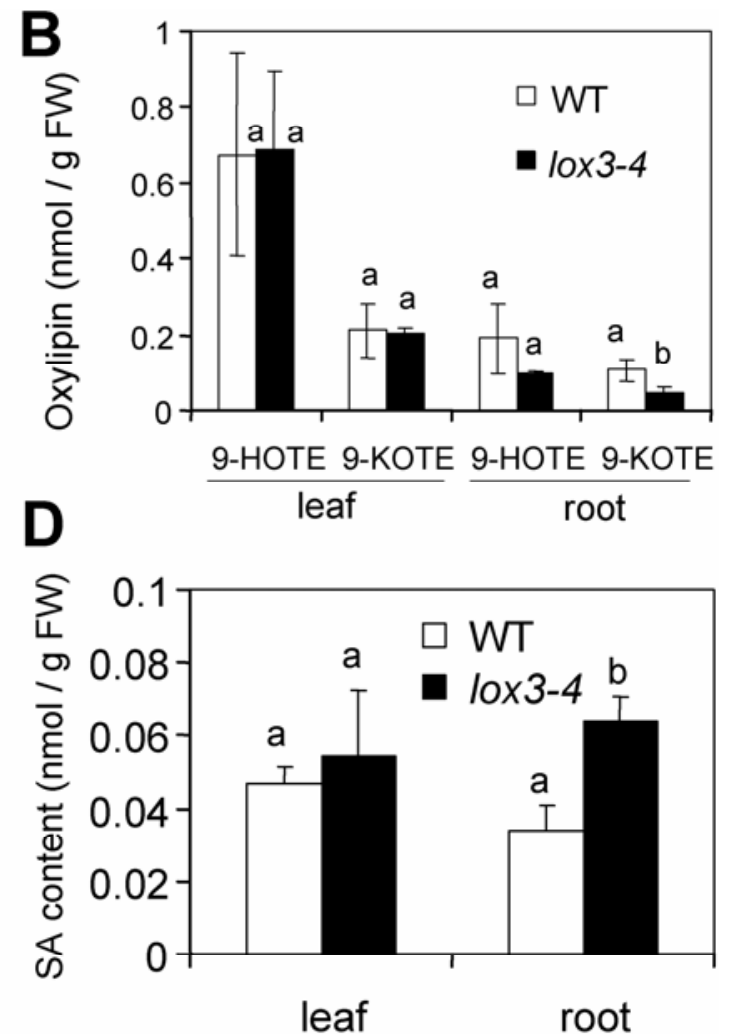

$\mathbf{F}$

WT Iox3-4 WT lox3-4

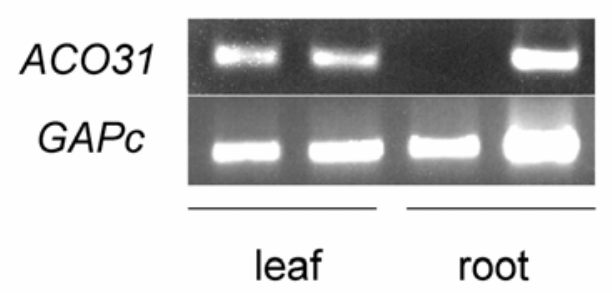

Fig. 6. Endogenous 9-oxylipins, jasmonic acid (JA), salicylic acid (SA), and ethylene (ET) levels and expression of ET biosynthetic gene ACO31 in lox3-4 mutant and near-isogenic wild-type (WT) tissues. A and B, 9-Oxylipin profiling was conducted by using gas chromatography/electron impact mass spectrometry (GC/EI-MS) in combination with reversed-phase high-performance liquid chromatography (RP-HPLC) in roots and leaves of the lox3-4 mutant versus WT. A, Linoleic acid-derived oxylipins; 9-HODE, (9S,10E,12Z)-9-hydroxy-10,12-octadecadienoic acid and 9-KODE, keto (9S,10E,12Z)-9-hydroxy10,12-octadecadienoic acid. B, Linolenic acid-derived oxylipins: 9-HOTE, (9S,10E,12Z,15Z)-9-hydroxy-10,12,15-octadecatrienoic acid and 9-KOTE, keto (9S,10E,12Z,15Z)-9-hydroxy-10,12,15-octadecatrienoic acid. Oxylipins were measured in two independently bred lines of the lox3-4 mutant or near-isogenic WT. Each genotype was replicated four times, and the data were expressed as means of four replicates. C, JA and D, SA levels were measured by using GC-MS as described by Engelberth and associates (2004). Four biological replicates with three seedlings at the V3 stage per each replicate were conducted for JA and SA content. E, ET levels were measured by GC as described by He and associates (1996). Four to five leaf segments from V3-stage seedlings or root segments from 1-week-old seedlings were used for each treatment, which was replicated three times. F, ACO31 expression in leaves and roots of lox3-4 mutants and WTs was analyzed by semiquantitative reverse-transcription polymerase chain reaction. Expression of glyceraldehyde-3-phosphate-dehydrogenase $(G A P c)$ was used as a quantitative standard. Different letters on the top of bars denote a significant difference $(P<0.05$, analysis of variance $)$ between WT versus mutant within same tissue analyzed by the SPSS program. 
2001; Oka et al. 1997; Veronico et al. 2006), to date, there is no conclusive data suggesting that the LOX pathway plays a role in regulating parasitism of maize by $\mathrm{RKN}$. The present study provided compelling evidence that a plant 9-LOX oxylipin pathway governs, in part, the interactions of a nematode with its host plant. Here, we showed that disruption of the maize 9-LOX gene $\mathrm{ZmLOX} 3$ resulted in approximately twofold increased nematode attraction to the host roots, and increased nematode fecundity. These data clearly indicated that lox3-4 mutants are significantly more susceptible to RKN, and that ZmLOX3 plays an important role in regulating parasitism of maize by RKN.

\section{ZmLOX3-mediated metabolism suppresses}

\section{JA- and SA-regulated pathways in roots.}

A striking difference between lox3-4 mutants and most of the reported Arabidopsis mutants constitutively expressing defense genes is that lox3-4 mutants produce simultaneously elevated levels of SA and JA in the roots but not leaves. SA is a major signal responsible for activation of defense against primarily biotrophic pathogens (Glazebrook 2005; Parbery 1996; Thomma et al. 2001), whereas JA plays a key role in the resistance against necrotrophic pathogens (Thomma et al. 2001). Further, early pharmacological as well as genetic studies using JA- and SA-signaling mutants suggested antagonistic interac-
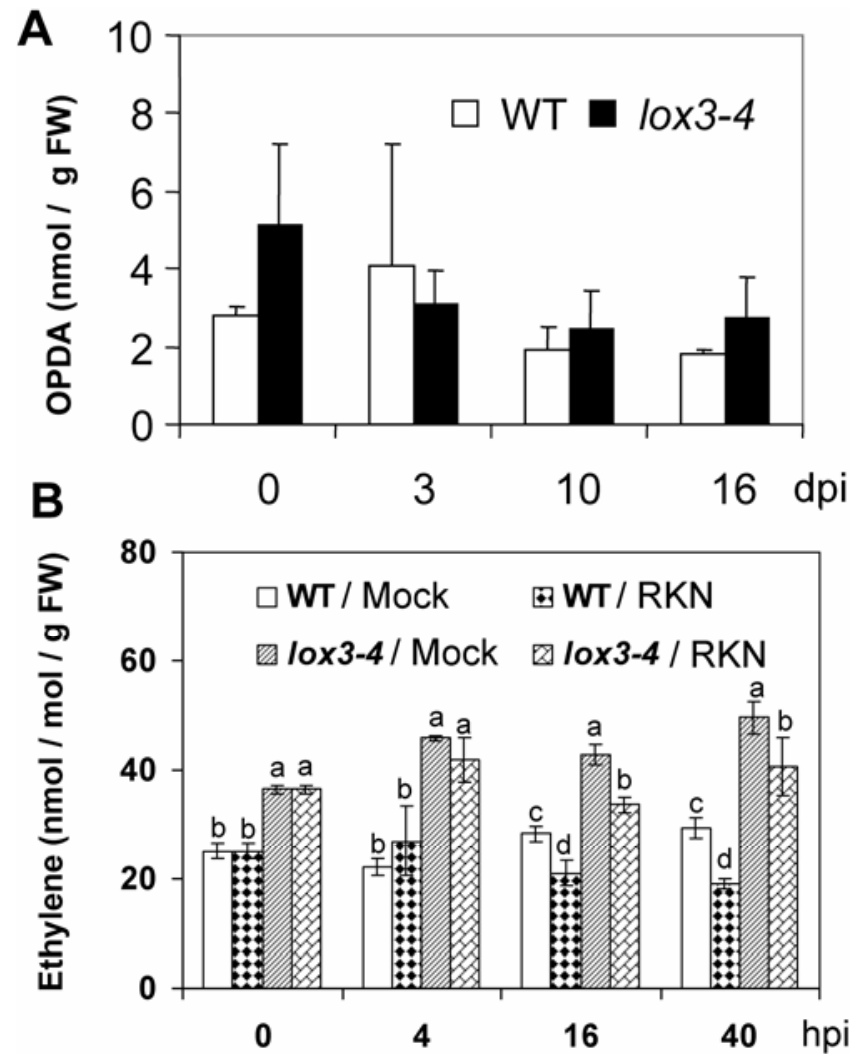

Fig. 7. Production of A, 12-oxo-phytodienoic acid (OPDA) and B, ethylene (ET) in the lox3-4 mutant and wild-type (WT) roots in response to root-knot nematode (RKN) infection. A, 12-OPDA was measured by gas chromatography-mass spectrometry method in two independently bred lines of lox3-4 mutant or WT, and the data were expressed as means of four replicates. B, ET levels were measured by gas chromatography as described by He and associates (1996). Following infection with second-stage juvenile RKN as described, two to three root segments were used for each treatment that was replicated three times. Mock treatments were inoculated with $\mathrm{H}_{2} \mathrm{O}$ only. The data were expressed as mean \pm standard deviation $(n=3)$. Different letters on the top of bars denote a significant difference $(P<0.05$, analysis of variance) among treatments within the same time point as analyzed by the SPSS program; dpi, days postinfection; hpi, hours postinfection. tion between these two signaling pathways, such that increased levels of one hormone generally resulted in decreased accumulation of the other (Cipollini et al. 2004; Dong 1998; Feys and Parker 2000; Traw et al. 2003). Our discovery of moderate simultaneous induction of both pathways indicates that signaling communication between the SA and JA pathways also can be synergistic. Synergistic mode of action of low (but not high) levels of SA and JA on defense gene expression in Arabidopsis and tobacco has been convincingly demonstrated in a recent study by Mur and associates (2006). This idea is further supported by recent Arabidopsis and sorghum microarray studies that indicate that, in response to JA, SA, and ET treatments, a large proportion of differentially expressed genes were coinduced by all three hormones (Salzman et al. 2005; Schenk et al. 2000). This suggests a more complex interaction between SA- and JA/ET-mediated regulation of gene expression than initially recognized. Collectively, our data suggest that a 9LOX-mediated pathway exhibits previously unrecognized suppressor activity on the biosynthesis of both SA and JA and expression of SA- and JA-responsive defense genes. Interestingly, we recently have found that lox3-4 mutants are significantly more resistant to the root-rotting fungal pathogen Exserohilum pedicellatum (Isakeit et al. 2007), which may be explained by the elevated levels of the major defense pathways in the mutant roots observed in this study.

Because JA- and SA-responsive genes were overexpressed in the lox3-4 mutant roots, we hypothesized that the genes involved in JA and SA biosynthesis also were overexpressed. Unfortunately, the SA biosynthetic pathway is still poorly understood in maize; therefore, we studied the genes from the well-established LOX pathway branches, the AOS branch of JA biosynthesis, and the GLV-producing HPL branch. We have isolated 12 maize LOX genes (Nemchenko et al. 2006;

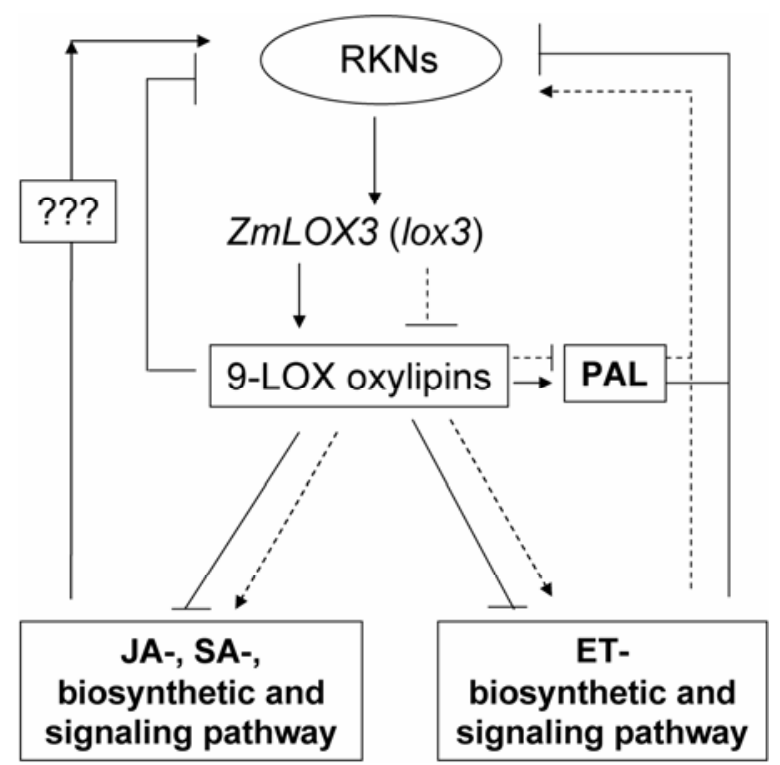

Fig. 8. Model of ZmLOX3-mediated signaling pathway in the root-specific regulation of jasmonic acid (JA)-, salicylic acid (SA)-, and ethylene (ET)-dependent defense pathways and resistance to root-knot nematodes (RKN). Solid and dashed lines indicate the hypothesized pathways in wild-type (WT) and lox3-4 mutant roots, respectively. In WT roots, ZmLOX3 suppresses JA-, SA-, and ET-dependent defense signaling pathways to allow the plant to grow intensively at early stages of germination and development, whereas mutation of $\mathrm{ZmLOX} 3$ (lox3) results in overproduction of phytohormones and overexpression of the defense genes regulated by these pathways. Disruption of the $Z m L O X 3$ gene results in the root's inability to induce the phenylalanine ammonia lyase $(P A L)$ gene, suggesting a role of PAL-mediated production of phenylpropanoids in susceptibility to RKN. 
M. Kolomiets et al. unpublished data), among which ZmLOX5 is a 9-LOX, whereas $\mathrm{ZmLOX7}$ and $\mathrm{ZmLOX8}$ are predicted to be 13-LOXs localized to chloroplasts (M. Kolomiets and I. Feussner, unpublished data). ZmLOX10 is the chloroplasttargeted 13-LOX that most likely functions in the biosynthesis of GLV (Nemchenko et al. 2006). Also, we previously identified eight OPR genes in maize, two of which, ZmOPR7 and ZmOPR8, are the closest homologs of the JAproducing OPR3 from Arabidopsis and, therefore, are hypothesized to be involved in JA biosynthesis (Zhang et al. 2005). Corroborating with the elevated levels of JA and constitutive expression of JA-responsive genes in the mutant roots, the genes encoding putative JA-producing enzymes, including $Z m L O X 8, Z m A O S$, ZmAOC, and ZmOPR8, were constitutively expressed at high levels in the unchallenged lox3-4 mutant roots but not leaves. A significant flower-specific shift in the amounts of oxylipins derived from both 9- and 13-LOX activities has been reported for tomato plants constitutively overexpressing the AOS gene (Miersch et al. 2004). Similar to our study, these transgenic plants produced higher levels of JA in a tissue-specific manner.

\section{Roles of SA and JA in resistance to nematodes.}

The fact that lox3-4 mutants produce elevated levels of JA and SA, two major signaling molecules in plant defenses against pathogens and herbivorous pests, and yet are more susceptible to RKN is rather intriguing and warrants more careful consideration regarding the role that these two hormones may have in plant-nematode interactions. Our data suggest that host resistance mechanisms to nematodes may not rely solely on the JA- and SA-mediated defenses, which are effective against microbial pathogens, but rather involve some other as yet unknown signals. Although SA function in plant-pathogen interactions has been studied extensively, surprisingly little is known about its role in plant defense mechanisms against nematodes. A recent study showed that tomato plants transformed with $N a h G$, a gene encoding salicylate hydroxylase that degrades SA, exhibited reduced resistance to $M$. javanica, suggesting a possible role of SA in tomato resistance against RKN (Branch et al. 2004). In contrast to that finding, lox3-4 mutants were more susceptible to RKN despite elevated levels of SA and increased transcript accumulation of SA-responsive genes such as $P R 1$. This uncertainty of the PRl's role in plant defenses against nematodes was emphasized further by a recent finding that transgenic Arabidopsis plants overexpressing ET-responsive element-binding protein displayed increased transcript levels of SA-regulated PRI but were not altered in its susceptibility to nematodes (Mazarei et al. 2007). Similar to $\mathrm{SA}$, currently, the role of JA in plant-nematode interactions is not well studied. Here, we showed that lox3-4 mutant roots produce increased levels of JA and the transcripts of JA-inducible ZmLOX10, ZmOPR8, and MPI (Nemchenko et al. 2006; Zhang et al. 2005). Despite this, lox3-4 mutants are significantly more susceptible to RKN. Contrary to our finding, previous reports showed that exogenous application of jasmonates increased resistance of plants to nematodes (Cooper et al. 2005; Oka et al. 1997). Thus, the function of JA in host-nematode interaction remains unclear, and obtaining conclusive evidence of its role will require the use of JA biosynthetic or signaling mutants.

\section{Antagonistic interactions}

between $\mathrm{ZmLOX3}$ and other 9- and 13-LOX branches.

Another surprising discovery of this study was that both genes encoding putative GLV-producing enzymes from the HPL branch, ZmLOX10 and HPL (Nemchenko et al. 2006), were constitutively expressed in the lox3-4 mutant roots, sug- gesting the possibility of increased production of GLV in the mutant roots but not leaves. GLV compounds exhibit direct antimicrobial activity and induce expression of several defenserelated genes (Matsui et al. 2006). Although it is unknown whether belowground organs are capable of producing GLV (Chehab et al. 2006), maize roots were shown to release volatile signals that attract entomopathogenic nematodes (Rasmann et al. 2005).

Our finding that lox3-4 overexpresses both the 13-LOX and the 9-LOX pathway genes provides genetic evidence of antagonistic interdependence among different branches of the LOX pathway that operates at a tissue-specific level. It is reasonable to speculate that this interaction may be controlled by a suppressive signaling activity of as yet unknown ZmLOX3derived oxylipins. Similar to our case, Göbel and associates (2003) reported that the 9-LOX-deficient potato plants showed increased levels of 13-LOX-derived oxylipins. Interestingly, plant roots and leaves are known to accumulate highly divergent levels of oxylipins, the so-called "oxylipin signature" of a plant organ, as exemplified by the most recent oxylipin profiling of potato organs (Stumpe et al. 2006). Our data suggest that one possible mechanism of such tissue-specific accumulation of different oxylipins may be antagonistic interdependence of different branches of the LOX pathways. In this regard, we noted that, in wild-type plants, $\mathrm{ZmLOX3}$ is expressed predominantly in roots and mesocotyls but not in the V3 stage or mature leaves (Gao et al. 2007). Recent data by Vellosillo and associates (2007) showed that Arabidopsis roots exhibit strong 9-LOX activity and the 9-LOX-defective mutants display an increased number of lateral roots. Interestingly, mutants insensitive to the 9-LOX-derived oxylipin 9-HOT exhibited increased susceptibility to a bacterial pathogen, Pseudomonas syringae pv. tomato (Vellosillo et al. 2007), indicating that some 9-oxylipins not only are endogenous modulators of root development but also signaling molecules for defense response.

\section{Role of ET in the increased susceptibility of lox3-4 mutant to RKN.}

Perhaps the most important finding about lox3-4 mutants that may relate directly to their increased susceptibility to RKN is that they constitutively express $A C O 31$, an ET biosynthetic gene, and, as a result, overproduce ET in the roots but not in the leaves. A recent study reported that ET-insensitive mutants etr1, ein2, and ein3 in Arabidopsis were more resistant to the cyst nematode Heterodera schachtii compared with wild-type plants (Wubben et al. 2001). Thus, it is reasonable to suggest that ET might be involved in increased susceptibility of the lox3-4 mutant to RKN. Moreover, similar to a previous report (Wubben et al. 2001), we found that lox3-4 mutant attracted more juveniles and more galls were formed on the mutant roots. The fact that RKN infection failed to enhance ET production in both wild-type and mutant roots suggests that constitutive rather than induced higher levels of ET in lox3-4 may be responsible for their increased attractiveness and susceptibility to RKN. To test this hypothesis directly, double and triple mutants between lox3-4 and available maize ET biosynthetic mutants (Young et al. 2004) are being generated in our laboratory.

\section{Is PAL important for resistance to nematodes?}

Because lox3-4 mutants exhibited elevated levels of JA, SA, and ET, the major signals cumulatively regulating expression of many defense genes, including $P A L$, it was rather surprising that lox3-4 mutant roots lost their ability to induce the $P A L$ gene. This gene clearly was upregulated by RKN in near-isogenic wild-types, suggesting that a functional ZmLOX3-mediated signal transduction pathway is required for $\mathrm{RKN}$-induced expression of this gene. PAL is a key enzyme involved in the 
biosynthesis of an array of phenylpropanoid-derived phytoalexins with potent antimicrobial activity (Grayer and Kokubun 2001). The absence of expression of $P A L$ suggests that this specific PAL isoform and its metabolites may be responsible, in part, for increased susceptibility of the lox3-4 mutant to RKN.

Oxylipins produced specifically by ZmLOX3 are unknown.

Although only a relatively small number of endogenous maize oxylipins can be measured by techniques currently available to us, we attempted to identify and quantify those oxylipins that may be specifically produced by the ZmLOX3mediated pathway and, thus, may play a role in maize-RKN interactions. Among the 28 oxylipins quantified in this study, noninfected mutant roots, but not leaves, were found to contain moderately lower levels of several 9-LOX-derived oxylipins, including 9-HODE, 9-KODE, and 9-KOTE (at the significance level $P<0.05$ ), as expected from a disruption of a 9-LOX gene. However, no statistically significant difference in the oxylipin content was detected between wild types and the mutants upon RKN infection (data not shown). This could be explained by the fact that lox3-4 mutants overexpress three other lipoxygenases, LOX5 (a 9-LOX), LOX8, and LOX10 (both 13-LOXs) that may compensate for the lack of the LOX3 deficiency upon infection with nematodes in terms of oxylipin production. To identify oxylipins produced specifically by LOX3, double and triple mutants between lox3, lox5, and lox10 are being generated. Oxylipin profiling of these mutants will allow us to pinpoint specific products synthesized by these different LOX isoforms.

The fact that the lox3-4 mutant roots, but not leaves, exhibited reduced content of 9-oxylipins agrees with the previously reported root-specific expression of $Z m L O X 3$ (Gao et al. 2007). Specifically, that study shows that $Z m L O X 3$ mRNA is not detectable in the V3 stage, nontreated leaves, but is induced transiently by infection with Cochliobolus heterostrophus. Because lox3-4 mutants are more resistant to $C$. heterostrophus and to another leaf-infecting fungal pathogen, Colletotrichum graminicola, we suggested that the ZmLOX3-mediated 9oxylipins may be required for normal fungal pathogenicity. The present study clearly demonstrated that the 9-oxylipin content (Fig. 6) and expression of the defense genes (data not shown) in the nontreated lox3-4 leaves is not altered compared with the wild type. Thus, it is reasonable to predict that the pathogen-inducible $Z m L O X 3$-derived 9-oxylipins (yet to be identified) facilitate fungal pathogenicity (Gao et al. 2007).

\section{Hypothetical model for physiological function of ZmLOX3 in growth and resistance to RKN.}

Taken together, our data indicate that mutation of $\mathrm{ZmLOX3}$ results in root-specific simultaneous overproduction of major defense hormones JA, SA, and ET and overexpression of a series of defense-related genes regulated by corresponding signaling pathways. Based on these findings, we propose a hypothetical model (Fig. 8) in which ZmLOX3 functions as a major suppressor of several defense pathways in wild-type roots, possibly by producing a novel hormone-like 9-LOX-derived oxylipin yet to be identified, for which this root-specific defense inhibitory activity has not been recognized previously. Moreover, $Z m L O X 3$ in wild-type tissues is expressed primarily in underground organs (Gao et al. 2007) and induced by RKN in the wild type, which suggests that nematodes could induce ZmLOX3 to suppress general defense processes in roots (Fig. 8). If $\mathrm{ZmLOX} 3$ functions as a suppressor of the defense pathways, then what is the function of this gene in healthy, untreated tissues? The preferential expression of $Z m L O X 3$ in underground organs and the increased transcript accumulation during early stages of germination (Wilson et al. 2001) suggest that ZmLOX3 most likely functions to suppress major defense pathways in order to allocate most of the energy into vegetative growth at early stages of germination. Indeed, there is a cost in fitness of overexpression of defense pathways in plants (Baldwin 1998). In agreement with this hypothesis, examination of morphological traits of homozygote and heterozygote lox3-4 mutants revealed that mutant plants were shorter and senesced earlier than the near-isogenic wild types. However, no other visible abnormalities (color, leaf shape, seed traits, and so on) associated with the lox3-4 mutation were observed throughout all stages of plant development.

In summary, we hypothesize that lox3-4 mutants are more susceptible to RKN due to an increased level of ET which may override increased basal levels of general defenses (e.g., increased MPI and PR1) and the lack of inducibility of PAL. Although the function of JA- and SA-signaling pathways in maize-nematode interactions remains complex, this study indicates that some 9-LOX-derived oxylipins act as signals positively regulating early development processes by suppressing expression of defense pathways in a root-specific manner.

\section{MATERIALS AND METHODS}

\section{Plant materials.}

The maize lox3-4 mutant was generated by $M u$-transposable element-insertional mutagenesis as described previously (Gao et al. 2007). Both the mutant and wild type are NILs at the $\mathrm{BC}_{4} \mathrm{~F}_{5}$ genetic stage in $\mathrm{B} 73$ background. For observation of germination and early seedling growth defects, lox3-4 mutants and wild-type seedlings were grown for 5 days in a hydroponics system as described by Djonovic and associates (2006). For RKN infection experiments, seed were sown in conical pots $(15$ by $3 \mathrm{~cm}$ ) filled with steam-sterilized coarse sand/peat mix $(6: 1, \mathrm{vol} / \mathrm{vol})$. Plants were grown in a greenhouse with temperatures ranging from 25 to $34^{\circ} \mathrm{C}$.

\section{Attraction of nematodes to maize roots by using mini-olfactometer system.}

The six-arm olfactometer assay was conducted as described by Rasmann and associates (2005) with some modifications. Briefly, the mini-olfactometer was constructed by connecting a central petri dish ( $7 \mathrm{~cm}$ in diameter) and six $15-\mathrm{ml}$ conical centrifuge Falcon tubes with six equally distributed side arms (1.6 $\mathrm{cm}$ in length of basal portion of a $200-\mu \mathrm{l}$ pipette tip). To allow the RKN to have equal chance to be attracted to the maize roots, three 7-day-old wild-type and three lox3-4 mutant seedlings were transplanted to each of the tubes filled with sterilized sand at alternating sites. One day after transplanting, $6,000 \mathrm{~J} 2$ in $5 \mathrm{ml}$ of $\mathrm{H}_{2} \mathrm{O}$ were added onto the center of the petri dish. After the seedlings were cultured under $14 \mathrm{~h}$ of daylight with $120 \mu \mathrm{mol} \mathrm{m} \mathrm{m}^{-2} \mathrm{~s}^{-1}$ at 25 to $28^{\circ} \mathrm{C}$ for 4 days, the sand of each tube was collected and filtered and the number of $\mathrm{J} 2$ RKN was counted using a microscope. Three six-arm olfactometers were used as replicates. For each replicate, the number of nematodes that migrated to either wild-type or mutant seedlings was summed and the average number of nematodes was calculated. The number of nematodes was expressed as the average from the three replicates. The experiments were repeated three times and consistent data were obtained.

\section{Infection with nematodes and data analysis.}

The $M$. incognita (population no. 98-1) used in this study was a composite of several isolates from cotton and was maintained on tomato (Lycopersicon esculentum 'Rutgers') in a greenhouse. Eggs for inoculum were extracted from infected tomato using 0.06\% NaOCl (Hussey and Barker 1973). The 
eggs were placed on nylon screens with $20-\mu \mathrm{m}$ pores and incubated in water at $25^{\circ} \mathrm{C}$; freshly hatched $\mathrm{J} 2$ that migrated through the screens were collected for use as inoculum (Vrain 1977). Seedlings (V2 stage, 10 days old) were inoculated with a suspension of 5,000 freshly hatched $\mathrm{J} 2$ by pipetting the nematodes into three depressions in the soil that were spaced equidistant around the base of the seedling. Control plants received the same volume of sterile water. For gene expression studies, wild-type and mutant seed were planted in conical pots $(6.5 \mathrm{~cm}$ in diameter, $25 \mathrm{~cm}$ in depth), one seed per pot. To test lox3-4 mutants and wild types for resistance to RKN, individual 2-week-old maize seedlings (V3 stage) were transplanted into $15-\mathrm{cm}$-diameter pots filled with a coarse sand/peat mix $(6: 1, \mathrm{vol} / \mathrm{vol})$ and then inoculated with a suspension of 10,000 nematode eggs. A completely randomized experimental design was used with a minimum of 10 replications for each treatment. Plants were harvested at 8 weeks after inoculation and the roots washed to remove adhering soil, blotted with a paper towel, and weighed. Nematode eggs were extracted from root tissue using 0.12\% $\mathrm{NaOCl}$ (Hussey and Barker 1973). Extracted eggs were counted using a stereomicroscope. The experiments were replicated three times and similar results were obtained. Data were analyzed using the general linear model of SAS (SAS Institute, Inc., Cary, NC, U.S.A.), with mean separations by least significant difference (LSD) when appropriate.

\section{RNA extraction and sqRT-PCR analysis.}

Infected roots from mutant and wild-type plants were harvested at designated times after inoculation and the roots washed gently to remove adhering soil under tap water, blotted with a paper towel, subsequently frozen in liquid $\mathrm{N}_{2}$, and stored immediately at $-80^{\circ} \mathrm{C}$. Total RNA from roots at various time points was extracted using TRI reagent (Molecular Research Center Inc., Cincinnati, OH, U.S.A.) according to the manufacturer's protocol. All primers of genes for LOX pathways and JA- and SA-responsive and ET biosynthesis used in this study for sqRT-PCR reactions are listed in Table 1. Glyceraldehyde-3-phosphate-dehydrogenase $(G A P c)$ was used as internal control as described by Farag and associates (2005). To prepare cDNA for RT-PCR analysis, RNA samples were treated with RNase-free rDNase at $37^{\circ} \mathrm{C}$ for 30 min using the DNA-free kit (Ambion Inc., Austin, TX, U.S.A.) prior to cDNA synthesis. First-strand cDNA synthesis from RNA was carried out simultaneously for all samples using the FirstStrand Synthesis Kit (Amersham Biosciences UK Limited, Little Chalfont, Buckinghamshire, U.K.) with Not I-d(T) ${ }_{18}$ primer following the manufacturer's guidelines. The firststrand cDNA from each sample was diluted to ensure equal amounts of cDNA template for quantification of gene expression by sqRT-PCR. To define the optimal number of PCR cy- cles for linear amplification of each gene, a range of PCR amplifications was performed. cDNA template was dissociated for $10 \mathrm{~min}$ at $94^{\circ} \mathrm{C}$, followed by PCR cycling in a GeneAmp PTC-100 cycler: PCR amplification of GAPc gene was run at 23 cycles (each cycle: $30 \mathrm{~s}$ at $94^{\circ} \mathrm{C}, 45 \mathrm{~s}$ at $58^{\circ} \mathrm{C}$, and $1 \mathrm{~min}$ at $72^{\circ} \mathrm{C}$ ). The same cycles were performed within the same gene for both wild-type and mutant RNA. Amplified DNA fragments were separated on $1.5 \%$ (wt/vol) agarose gels and recorded under UV light after ethidium bromide staining. The negative control for sqRT-PCR was DNase-treated and cleaned RNA reactions without reverse transcription. The experiment was carried out with two independent biological replicates, each repeated technically at least twice with similar results.

\section{Oxylipin profiling.}

Oxylipin profiling in the roots and leaves of the lox3-4 mutant and wild type infected with RKN in a greenhouse was conducted as described by Stumpe and associates (2005). The tissues from three plants were harvested and combined into a single sample at designated times, frozen in liquid $\mathrm{N}_{2}$, and lyophilized. Oxylipin data from the analysis of two independently bred lines of the lox3-4 mutant (4-1 and 4-2) or wild type (5-1 and 5-2) were combined as a data from a single genotype. Each genotype was replicated four times, and the data were expressed as means of four replicates.

Measurement of endogenous JA, SA, OPDA, and ET levels.

For tissue-specific and RKN-induced analysis of SA and JA levels, 2-week-old seedlings (V3 stage) grown under $14 \mathrm{~h}$ of daylight with $120 \mu \mathrm{mol} \mathrm{m} \mathrm{m}^{-1}$ (Quantum Meter; Apogee Instruments, Logan, UT, U.S.A.) at 25 to $28^{\circ} \mathrm{C}$ in commercial soil (Metro-Mix 366; Scotts-Sierra Horticultural Products Company, Marysville, OH, U.S.A.) were harvested and frozen in liquid $\mathrm{N}_{2}$ immediately. Four biological replicates (three seedlings per replicate) were analyzed for JA and SA content. JA and SA levels were determined simultaneously by using GC-MS as described previously by Engelberth and associates (2004). 12-OPDA levels in the lox3-4 mutant and wild-type roots infected with RKN in a greenhouse were measured as described by Stumpe and associates (2005). The root tissues from three plants (representing one biological replicate) were harvested and combined into a single sample at designated times, frozen in liquid $\mathrm{N}_{2}$, and lyophilized. 12-OPDA data from the analysis of two independently bred lines of the lox3-4 mutant (4-1 and 4-2) or wild type (5-1 and 5-2) were combined as a data from a single genotype. Each genotype was replicated four times, and the data were expressed as means of four replicates.

Measurement of ET production was conducted as described by He and associates (1996) with some modifications. For ET measurement in leaves, the fourth leaves were excised from 2-

Table 1. Primer list for reverse-transcription polymerase chain reaction analyses performed in this study

\begin{tabular}{|c|c|c|c|}
\hline Gene name & Forward primer $\left(5^{\prime}-3^{\prime}\right)$ & Reverse primer $\left(5^{\prime}-3^{\prime}\right)$ & Primer source \\
\hline ZmPR1 & AACAATGGCACCGAGGCTAGCGT- & GTATGCATGACAGTCTAGTAGGG & This study (U82200) \\
\hline$Z m P A L$ & CGAGGTCAACTCCGTGAACG & GCTCTGCACGTGGTTGGTGA & Farag et al. (2005) \\
\hline $\mathrm{ZmOPR} 8$ & CCGCCTCAACGCTCTCCAGGAG & GACTGCTGATTGCTGTGCAAAT & Zhang et al. (2005) \\
\hline $\mathrm{ZmHPL}$ & TACGAGATGCTGCGGATG & CTCGAAGTCGTCGTAGCG & Farag et al. (2005) \\
\hline$Z m M P I$ & ATGAGCTCCACGGAGTGC & TCAGCCGATGTGGGGCGTC & Farag et al. (2005) \\
\hline ZmAOS & GTGCTCTTCGACATGGACAA & GAGAAGTACTTGTACAGCGCCC & He et al. (2005) \\
\hline $\mathrm{ZmAOC}$ & ACCAAGGTGCAGGAGCTGTA & GGTGTAGTTGTCGAGGGATG & AY488136 \\
\hline $\mathrm{ZmLOX} 3$ & AGCGCGGCTTCATCCACACCAT & ATACATGGTCCGTCTCGTGCCG & This study (AF329371) \\
\hline ZmLOX5 & GCGGTGATCGAGCCGTTCGTAATC & ACGGCGCAGCACAACAATTTACTACGAG & This study (DQ335763) \\
\hline $\mathrm{ZmLOX} 8$ & ATGAACGTGGTGGTCTGCGTCAGG & TACGCCACCGACGGGTTGTT & This study (DQ335766) \\
\hline $\mathrm{ZmLOX} 10$ & CGCCATCGACGACCTCTTCA & TCCGCACCTTGTGCACGTA & Nemchenko et al.(2006) (DQ335768) \\
\hline ZmACO31 & GTTCCCGTGATCGACTTCTC & GAAGATGTCCTCCCAGTCCA & AY359573 \\
\hline$G A P C$ & GCTAGCTGCACCACAAACTGC & TAGCCCCACTCGTTGTCGTAC & Farag et al. (2005) \\
\hline
\end{tabular}


week-old seedlings (V3 stage) grown as described above. Subsequently, a 7-cm-long section from the middle part of each leaf blade was excised, weighed, and transferred immediately into a $15-\mathrm{ml}$ Falcon tube and sealed with a plastic stopper. For analysis of ET production in the roots, to avoid woundinginduced ET production during sampling, lox3-4 mutant and wild-type seed were wrapped with wetted paper towel to allow germination in the dark for 1 week, and 5-cm-long root segments were excised from the tip, weighed, and placed immediately into a $6.2-\mathrm{ml}$ glass tube and sealed with a plastic stopper. Four to five root segments were used for each treatment that was replicated three times. For measuring ET production in response to $\mathrm{RKN} \mathrm{J} 2 \mathrm{~s}$, the root of a 5-day-old germinating seedling was placed into a plastic cylinder and inoculated with $100 \mathrm{~J} 2 \mathrm{~s}$ as described by Faske and Starr (2007). In brief, the seed were wrapped and germinated in a wetted germination paper (Anchor Paper Co., St. Paul, MN, U.S.A.) for 5 days, and roots were inserted inside a $7-\mathrm{cm}$-long plastic cylinder $(5$ $\mathrm{mm}$ in diameter) and covered with pasteurized sand through a gap ( 2 by $40 \mathrm{~mm}$ ) cut from the plastic cylinder in a big tray, then inoculated with RKN J2s. Mock treatments were inoculated with $\mathrm{H}_{2} \mathrm{O}$ only. To maintain high levels of humidity and prevent drying and exposure to light, the seedlings were covered with wetted paper towel and the tray was covered with aluminum foil. The 5 -cm-long root segments, including the tip, were excised from the seedlings at selected time points (hours) after infection. ET was measured by withdrawing a 1$\mathrm{ml}$ volume of headspace gas with a syringe and injecting it into a digital gas chromatograph (Photovac 10 plus; PerkinElmer, Inc., Norwalk, CT, U.S.A.) with a photo detector and compressed air (ultra zero grade; Praxair, Inc., Danbury, CT, U.S.A.) as carrier gas.

\section{Distribution of materials.}

Novel materials described in this publication may be available for noncommercial research purposes upon acceptance and signing of a material transfer agreement. In some cases, such materials may contain or be derived from materials obtained from a third party. In such cases, distribution of material will be subject to the requisite permission from any third-party owners, licensors, or controllers of all or parts of the material. Plant germplasm will not be made available except at the discretion of the owner and then only in accordance with all applicable governmental regulations. Obtaining any permission will be the sole responsibility of the requestor.

\section{ACKNOWLEDGMENTS}

This work was supported by the Texas Corn Producers Board, United States Department of Agriculture-Agricultural Research Service, Aflatoxin Workshop, the Texas Agricultural Experiment Station, and the NSF grant IOB-0544428 to M. Kolomiets. We thank M. Dickman for critical reading of the manuscript, B. Morgan and F. Wang for their excellent assistance with root-knot nematode inoculation and attraction experiments, T. Faske for the help with the statistical analysis of the data, C. He for his help with ET measurement, and E. Kolomiets for her help with manuscript preparation.

\section{LITERATURE CITED}

Abad, P., Favery, B., Rosso, M. N., and Castagnone-Sereno, P. 2003. Rootknot nematode parasitism and host response: Molecular basis of a sophisticated interaction. Mol. Plant Pathol. 4:217-224.

Alkharouf, N. W., Klink, V. P., Chouikha, I. B., Beard, H. S., MacDonald, M. H., Meyer, S., Knap, H. T., Khan, R., and Matthews, B. F. 2006. Timecourse microarray analyses reveal global changes in gene expression of susceptible Glycine max (soybean) roots during infection by Heterodera glycines (soybean cyst nematode). Planta 224:838-852.

Baldwin, I. T. 1998. Jasmonate-induced responses are costly but benefit plants under attack in native populations. Proc. Natl. Acad. Sci. U.S.A. 95:8113-8118.
Bate, N. J., and Rothstein, S. J. 1998. C-6-volatiles derived from the lipoxygenase pathway induce a subset of defense-related genes. Plant $\mathrm{J}$. 16:561-569.

Birkett, M. A., Campbell, C. A. M., Chamberlain, K., Guerrieri, E., Hick, A. J., Martin, J. L., Matthes, M., Napier, J. A., Pettersson, J., Pickett, J. A., Poppy, G. M., Pow, E. M., Pye, B. J., Smart, L. E., Wadhams, G. H., Wadhams, L. J., and Woodcock, C. M. 2000. New roles for cis-jasmone as an insect semiochemical and in plant defense. Proc. Natl. Acad. Sci. U.S.A. 97:9329-9334.

Blee, E. 2002. Impact of phyto-oxylipins in plant defense. Trends Plant Sci. 7:315-321.

Branch, C., Hwang, C. F., Navarre, D. A., and Williamson, V. M. 2004. Salicylic acid is part of the mi-1-mediated defense response to root-knot nematode in tomato. Mol. Plant-Microbe Interact. 17:351-356.

Cacas, J. L., Vailleau, F., Devoine, C., Ennar, N., Agnel, J. P., Tronchet, M., Ponchet, M., Blein, J. P., Roby, D., Triantaphylides, C., and Montillet, J. L. 2005. The combined action of 9 lipoxygenase and galactolipase is sufficient to bring about programmed cell death during tobacco hypersensitive response. Plant Cell Environ. 28:1367-1378.

Chehab, E. W., Raman, G., Walley, J. W., Perea, J. V., Banu, G., Theg, S., and Dehesh, K. 2006. Rice hydroperoxide lyases with unique expression patterns generate distinct aldehyde signatures in Arabidopsis. Plant Physiol. 141:121-134.

Cipollini, D., Enright, S., Traw, M. B., and Bergelson, J. 2004. Salicylic acid inhibits jasmonic acid-induced resistance of Arabidopsis thaliana to Spodoptera exigua. Mol. Ecol. 13:1643-1653.

Cooper, W. R., Jia, L., and Goggin, L. 2005. Effects of jasmonate-induced defenses on root-knot nematode infection of resistant and susceptible tomato cultivars. J. Chem. Ecol. 31:1953-1967.

Cordero, M. J., Raventos, D., and San Segundo, B. 1994. Expression of a maize proteinase inhibitor gene is induced in response to wounding and fungal infection: Systemic wound-response of a monocot gene. Plant J. 6:141-150.

Djonovic, S., Pozo, M. J., Dangott, L. J., Howell, C. R., and Kenerley, C. M. 2006. Sm1, a proteinaceous elicitor secreted by the biocontrol fungus Trichoderma virens induces plant defense responses and systemic resistance. Mol. Plant-Microbe Interact. 19:838-853.

Dong, X. 1998. SA, JA, ethylene, and disease resistance in plants. Curr. Opin. Plant Biol. 1:316-323.

Engelberth, J., Alborn, H. T., Schmelz, E. A., and Tumlinson, J. H. 2004. Airborne signals prime plants against insect herbivore attack. Proc. Natl. Acad. Sci. U.S.A. 101:1781-1785.

Engelberth, J., Seidl-Adams, I., Schultz, J. C., and Tumlinson, J. H. 2007. Insect elicitors and exposure to green leafy volatiles differentially upregulate major octadecanoids and transcripts of 12-oxo phytodienoic acid reductases in Zea mays. Mol Plant-Microbe Interact. 20:707-716.

Fammartino, A., Cardinale, F., Göbel, C., Mène-Saffrané, L., Fournier, J., Feussner, I., and Esquerré-Tugayé, M. T. 2007. Characterization of a divinyl ether biosynthetic pathway specifically associated with pathogenesis in tobacco. Plant Physiol. 143:378-388.

Farag, M. A., Fokar, M., Zhang, H. A., Allen, R. D., and Pare, P. W. 2005. (z)-3-Hexenol induces defense genes and downstream metabolites in maize. Planta 220:900-909.

Faske, T. R., and Starr, J. 2007. Cotton root protection from plant-parasitic nematodes by abamectin-treated seed. J. Nematol. 39:27-30.

Feussner, I., and Wasternack, C. 2002. The lipoxygenase pathway. Annu. Rev. Plant Biol. 53:275-297.

Feys, B. J., and Parker, J. E. 2000. Interplay of signaling pathways in plant disease resistance. Trends Genet. 16:449-455.

Gao, X., Shim, W. B., Göbel, C., Kunze, S., Feussner, I., Meeley, R., Balint-Kurti, P., and Kolomiets, M. 2007. Disruption of a maize 9lipoxygenase results in increased resistance to fungal pathogens and reduced levels of contamination with the mycotoxin fumonisin. Mol. Plant-Microbe Interact. 20:922-933.

Gheysen, G., and Fenoll, C. 2002. Gene expression in nematode feeding sites. Annu. Rev. Phytopathol. 40:191-219.

Glazebrook, J. 2005. Contrasting mechanisms of defense against biotrophic and necrotrophic pathogens. Annu. Rev. Phytopathol. 43:205-227.

Göbel, C., Feussner, I., Schmidt, A., Scheel, D., Sanchez-Serrano, J., Hamberg, M., and Rosahl, S. 2001. Oxylipin profiling reveals the preferential stimulation of the 9-lipoxygenase pathway in elicitor-treated potato cells. J. Biol. Chem. 276:6267-6273.

Göbel, C., Feussner, I., Hamberg, M., and Rosahl, S. 2002. Oxylipin profiling in pathogen-infected potato leaves. Biochim. Biophys. Acta 1584:55-64.

Göbel, C., Feussner, I., and Rosahl, S. 2003. Lipid peroxidation during the hypersensitive response in potato in the absence of 9-lipoxygenases. J. Biol. Chem. 278:52834-52840.

Grayer, R. J., and Kokubun, T. 2001. Plant-fungal interactions: The search 
for phytoalexins and other antifungal compounds from higher plants. Phytochemistry 56:253-263.

Hamberg, M., Sanz, A., Rodriguez, M. J., Calvo, A. P., and Castresana, C. 2003. Activation of the fatty acid alpha-dioxygenase pathway during bacterial infection of tobacco leaves. Formation of oxylipins protecting against cell death. J. Biol. Chem. 278:51796-51805.

Hammerschmidt, R. 1999. Phytoalexins: What have we learned after 60 years? Annu. Rev Phytopathol. 37:285-306.

He, C., Finlayson, S. A., Drew, M. C., Jordan, W. R., and Morgan, P. W. 1996. Ethylene biosynthesis during aerenchyma formation in roots of maize subjected to mechanical impedance and hypoxia. Plant Physiol. 112:1679-1685.

Howe, G. A., and Schilmiller, A. L. 2002. Oxylipin metabolism in response to stress. Curr. Opin. Plant Biol. 5:230-236.

Hussey, R. S., and Barker, K. R. 1973. Comparison of methods of collecting inocula of Meloidogyne spp., including a new technique. Plant Dis. Rep. 57:1025-1028.

Isakeit, T., Gao, X., and Kolomiets, M. 2007. Increased resistance of a maize mutant lacking the 9-lipoxigenase gene, $Z m L O X 3$, to root rot caused by Exserohilum pedicellatum. J. Phytopathol. 155:758-760.

Jensen, A. B., Poca, E., Rigaud, M., Freyssinet, G., and Pages, M. 1997. Molecular characterization of 12 lipoxygenase from maize embryos. Plant Mol. Biol. 33:605-614.

Kishimoto, K., Matsui, K., Ozawa, R., and Takabayashi, J. 2006. Etr1-, jar1and pad2-dependent signaling pathways are involved in C6-aldehydeinduced defense responses of Arabidopsis. Plant Sci. 171:415-423.

Kolomiets, M., Navarro, P., Zhang, J., Yalpani, N., Simmons, C., Meeley, B., and Duvick, J. 2004. Identification and characterization of the lipoxygenase gene family of maize. Mycopathologia 157:501.

Kolomiets, M. V., Chen, H., Gladon, R. J., Braun, E. J., and Hannapel, D. J. 2000. A leaf lipoxygenase of potato induced specifically by pathogen infection. Plant Physiol. 124:1121-1130.

Kolomiets, M. V., Hannapel, D. J., Chen, H., Tymeson, M., and Gladon, R.J. 2001. Lipoxygenase is involved in the control of potato tuber development. Plant Cell 13:613-626.

Leone, A., Melillo, M. T., and Bleve-Zacheo, T. 2001. Lipoxygenase in pea roots subjected to biotic stress. Plant Sci. 161:703-717.

Matsui, K., Minami, A., Hornung, E., Shibata, H., Kishimoto, K., Ahnert, V., Kindl, H., Kajiwara, T., and Feussner, I. 2006. Biosynthesis of fatty acid derived aldehydes is induced upon mechanical wounding and its products show fungicidal activities in cucumber. Phytochemistry 67:649-657.

Mazarei, M., Elling, A. A., Maier, T. R., Puthoff, D. P., and Baum, T. J. 2007. Gmerebp1 is a transcription factor activating defense genes in soybean and Arabidopsis. Mol. Plant-Microbe Interact. 20:107-119.

Miersch, O., Weichert, H., Stenzel, I., Hause, B., Maucher, H., Feussner, I., and Wasternack, C. 2004. Constitutive overexpression of allene oxide cyclase in tomato (Lycopersicon esculentum cv. Lukullus) elevates levels of some jasmonates and octadecanoids in flower organs but not in leaves. Phytochemistry 65:847-856.

Mur, L. A., Kenton, P., Atzorn, R., Miersch, O., and Wasternack, C., 2006. The outcomes of concentration-specific interactions between salicylate and jasmonate signaling include synergy, antogonism, and oxidative stress leading to cell death. Plant Physiol. 140:249-262.

Nemchenko, A., Kunze, S., Feussner, I., and Kolomiets, M. 2006. Duplicate maize 13-lipoxygenase genes are differentially regulated by circadian rhythm, cold stress, wounding, pathogen infection and hormonal treatments. J. Exp. Bot. 57:3767-3779.

Oka, Y., Chet, I., and Spiegel, Y. 1997. An immunoreactive protein to wheat-germ agglutinin antibody is induced in oat roots following invasion of the cereal cyst nematode Heterodera avenae, and by jasmonate. Mol. Plant-Microbe Interact. 10:961-969.

Parbery, D. G. 1996. Trophism and the ecology of fungi associated with plants. Biol. Rev. Cambridge Philos. Soc. 71:473-527.

Porta, H., and Rocha-Sosa, M. 2002. Plant lipoxygenases. Physiological and molecular features. Plant Physiol. 130:15-21.

Prost, I., Dhondt, S., Rothe, G., Vicente, J., Rodriguez, M. J., Kift, N., Carbonne, F., Griffiths, G., Esquerre-Tugaye, M. T., Rosahl, S., Castresana, C., Hamberg, M., and Fournier, J. 2005. Evaluation of the antimicrobial activities of plant oxylipins supports their involvement in defense against pathogens. Plant Physiol. 139:1902-1913.
Rasmann, S., Kollner, T. G., Degenhardt, J., Hiltpold, I., Toepfer, S. Kuhlmann, U., Gershenzon, J., and Turlings, T. C. J. 2005. Recruitment of entomopathogenic nematodes by insect-damaged maize roots. Nature 434:732-737.

Rusterucci, C., Montillet, J. L., Agnel, J. P., Battesti, C., Alonso, B., Knoll, A., Bessoule, J. J., Etienne, P., Suty, L., Blein, J. P., and Triantaphylides, C. 1999. Involvement of lipoxygenase-dependent production of fatty acid hydroperoxides in the development of the hypersensitive cell death induced by cryptogein on tobacco leaves. J. Biol. Chem. 274:36446-36455.

Salzman, R. A., Brady, J. A., Finlayson, S. A., Buchanan, C. D., Summer, E. J., Sun, F., Klein, P. E., Klein, R. R., Pratt, L. H., Cordonnier-Pratt, M. M., and Mullet, J. E. 2005. Transcriptional profiling of sorghum induced by methyl jasmonate, salicylic acid, and aminocyclopropane carboxylic acid reveals cooperative regulation and novel gene responses. Plant Physiol. 138:352-368.

Santino, A., Iannacone, R., Hughes, R., Casey, R., and Mita, G. 2005. Cloning and characterisation of an almond 9-lipoxygenase expressed early during seed development. Plant Sci. 168:699-706.

Schenk, P. M., Kazan, K., Wilson, I., Anderson, J. P., Richmond, T., Somerville, S. C., and Manners, J. M. 2000. Coordinated plant defense responses in Arabidopsis revealed by microarray analysis. Proc. Natl. Acad. Sci. U.S.A. 97:11655-11660.

Schmelz, E. A., Alborn, H. T., and Tumlinson, J. H. 2003. Synergistic interactions between volicitin, jasmonic acid and ethylene mediate insectinduced volatile emission in Zea mays. Physiol. Plant. 117:403-412.

Stumpe, M., Carsjens, J. G., Stenzel, I., Gobel, C., Lang, I., Pawlowski, K., Hause, B., and Feussner, I. 2005. Lipid metabolism in arbuscular mycorrhizal roots of Medicago truncatula. Phytochemistry 66:781791.

Stumpe, M., Gobel, C., Demchenko, K., Hoffmann, M., Klosgen, R. B., Pawlowski, K., and Feussner, I. 2006. Identification of an allene oxide synthase (CYP74c) that leads to formation of alpha-ketols from 9-hydroperoxides of linoleic and linolenic acid in below-ground organs of potato. Plant J. 47:883-896.

Thomma, B. P. H. J., Penninckx, I. A. M. A., Broekaert, W. F., and Cammue, B. P. A. 2001. The complexity of disease signaling in Arabidopsis. Curr. Opin. Immun. 13:63-68.

Traw, M. B., Kim, J., Enright, S., Cipollini, D. F., and Bergelson, J. 2003. Negative cross-talk between salicylate- and jasmonate-mediated pathways in the Wassilewskija ecotype of Arabidopsis thaliana. Mol. Ecol. 12:1125-1135.

van Loon, L. C., Geraats, B. P. J., and Linthorst, H. J. M. 2006. Ethylene as a modulator of disease resistance in plants. Trends Plant Sci. 11:184-191.

Veronico, P., Giannino, D., Mellillo, M. T., Leone, A., Reyes, A., Kennedy, M. W., and Bleve-Zacheo, T. 2006. A novel lipoxygenase in pea roots. Its function in wounding and biotic stress. Plant Physiol. 141:1045-1055.

Vellosillo, T., Martinez, M., Lopez, M. A., Vicente, J., Cascon, T., Dolan, L., Hamberg, M., and Castresana, C. 2007. Oxylipins produced by the 9-lipoxygenase pathway in Arabidopsis regulate lateral root development and defense responses through a specific signaling cascade. Plant Cell 19:831-847.

Vrain, T. C. 1977. Technique for collection of larvae of Meloidogyne spp. and a comparison of eggs and larvae as inocula. J. Nematol. 9:249-251.

Williamson, V. M. 1999. Plant nematode resistance genes. Curr. Opin. Plant Biol. 2:327-331.

Wilson, R. A., Gardner, H. W., and Keller, N. P. 2001. Cultivar-dependent expression of a maize lipoxygenase responsive to seed infesting fungi. Mol. Plant-Microbe Interact. 14:980-987.

Windham, G. L. 1998. Corn. Pages 335-357 in: Plant Nematode Interactions. K. R. Barker, G. A. Pederson, and G. L. Windham, eds. American Society of Agronomy, Madison, WI, U.S.A.

Wubben, M. J. E., Su, H., Rodermel, S. R., and Baum, T. J. 2001. Susceptibility to the sugar beet cyst nematode is modulated by ethylene signal transduction in Arabidopsis thaliana. Mol. Plant-Microbe Interact. 14:1206-1212.

Young, T. E., Meeley, R. B., and Gallie, D. R. 2004. ACC synthase expression regulates leaf performance and drought tolerance in maize. Plant $\mathrm{J}$. 40:813-825.

Zhang, J. L., Simmons, C., Yalpani, N., Crane, V., Wilkinson, H., and Kolomiets, M. 2005. Genomic analysis of the 12-oxo-phytodienoic acid reductase gene family of Zea mays. Plant Mol. Biol. 59:323-343. 